\title{
O PROCEDIMENTO DE ANÁLISE EM PROJETO: DO PROGRAMA ARQUITETÔNICO À AVALIAÇÃO DE EDIFÍCIOS
}

\section{PROCEDURES FOR DESIGN ANAL YSIS: FROM PROGRAM TO BUILDING EVALUATION}

Daniel de Carvalho Moreira ${ }^{1}$

Universidade Estadual de Campinas, Faculdade de Engenharia Civil, Arquitetura e Urbanismo, Campinas - SP

Editor Chefe

damore@fec.unicamp.br

Regina C. Ruschel ${ }^{2}$ Universidade Estadual de Campinas, Faculdade de Engenharia Civil, Arquitetura e Urbanismo, Campinas - SP Editor Chefe parc@fec.unicamp.br

\section{Editorial}

Ponto de referência central da filosofia moderna, o trabalho de René Descartes representou uma alternativa decisiva, influente e duradoura ao desenvolvimento do pensamento grego que dominou a epistemologia por mais de dois mil anos. Nos séculos anteriores à Descartes, as contribuições de Platão e Aristóteles para a filosofia viram-se saturadas de implicações teológicas cristãs, pouco favoráveis às ambições científicas e matemáticas que se concretizaram nos anos do Renascimento e do Barroco na Europa. As considerações sobre as estruturas e os procedimentos do pensamento racional para evitar incorrer em erro diante da observação de um fenômeno, colocaram o método cartesiano como a tradução dos fundamentos da ciência moderna. Apesar de tamanho impacto, nos dias de hoje os procedimentos descritos por Descartes tendem a ser erroneamente interpretados como limitados, lineares ou metódicos, embora dificilmente a construção de uma ideia ou de uma proposta científica seja capaz de ignorar os procedimentos de análise, síntese e avaliação.

Testemunho da permanência das ideias descritas em o "Discurso do Método", as iniciativas de arquitetos e engenheiros da década de 1960 em estabelecer uma base científica para os estudos em processo de projeto partiram da mesma tríade (JONES, 1963). Ainda hoje, as etapas de análise, síntese e avaliação regem os processos de concepção de objetos e de edifícios e permitem elucidar a ação do projetista durante o processo de projeto (ANDRADE; RUSCHEL; MOREIRA, 2011). O primeiro movimento em projeto é o da análise, onde são identificadas as partes que constituem o contexto em que ocorre a intervenção do projetista ou as partes daquilo que será a forma proposta. Independentemente da primeira ação permitir a compreensão da situação ou dar início ao desenvolvimento do produto, ela é inequivocamente uma análise. A natureza da análise, tanto na compreensão do contexto como na proposição da forma, é descrita por Beltramin (2015) segundo a obra de René Descartes (2004) e Simon Unwin (1997):

'Na etimologia, o termo 'análise' é originário do grego 'analyein', que significa 'decompor' ou 'soltar'. O filósofo moderno René Descartes descreveu o exercício da análise como a decomposição de algo em partes para a sua compreensão enquanto todo. Nas palavras de Simon Unwin,

How to cite this article:

MOREIRA, Daniel de Carvalho; RUSCHEL, Regina C.. O procedimento de análise em projeto: do programa arquitetônico à avaliação de edifícios. PARC Pesquisa em Arquitetura e Construção, Campinas, v. 6, n. 1, p. 69-71, abr./jun. 2015. Disponível em: $<$ http://periodicos.sbu.unicamp.br/ojs/index.php/parc/article/view/8641793>. Acesso em: 19 Out. 2015 
'analisar algo significa liberar, soltar, expor para assimilar seus componentes e seu funcionamentoseus poderes'. Na arquitetura, a importância da análise não se dá apenas em sua compreensão enquanto produto, mas também na sua prática. A capacidade do arquiteto de fazer arquitetura pode ser desenvolvida a partir do estudo do trabalho de outros, da observação e da apreensão de formas como as diversas potencialidades da arquitetura são exploradas, aplicadas e administradas nos projetos".

A sequência de etapas do processo de projeto é também identificada com os procedimentos de análise, síntese e avaliação por Van Der Voordt e Van Wegen (2013), onde a etapa do programa de necessidades é identificada como essencialmente analítica. Ainda que a etapa de desenvolvimento do projeto inclua a análise e a avaliação, sua natureza é essencialmente de síntese dentro do processo como um todo. Já a avaliação pósocupação é a etapa do processo de projeto que trata da verificação e validação das alternativas materializadas no edifício, embora inclua a análise e a síntese em seus métodos e procedimentos.

O programa arquitetônico pode ser definido como a descrição do contexto onde o projeto vai operar ao estabelecer o problema que a forma deverá responder. Como um dos primeiros passos do processo de projeto, o desenvolvimento do programa é uma atividade analítica. A análise do contexto é um procedimento que busca os elementos essenciais da situação que envolve o edifício. O resultado apresentado pelo programa é a identificação e a organização das partes que compreendem o contexto, destacando os seus elementos principais. Esta divisão analítica é a estrutura do problema de projeto (MOREIRA, 2007).

No artigo "Programando a arquitetura da aprendizagem" as autoras - Sandra Leonora Alves e Doris C.C.K. Kowaltowski, da Universidade Estadual de Campinas apresentam elementos da arquitetura escolar e abordagens pedagógicas sob o ponto de vista do aluno, professor, atividade pedagógica e ambiente de aprendizagem. $\mathrm{O}$ artigo oferece um quadro síntese com informações que suportam o processo de projeto em coerência com a abordagem educacional - Tradicional, Behaviorista, Construtivista e Sócioconstrutivista - e suas necessidades. São organizadas informações que contribuirão para o aprimoramento do processo de projeto do edifício escolar, em especial para a elaboração do programa arquitetônico. A análise do contexto em que o edifício escolar opera é apresentada pelas autoras através da exposição dos fatores arquitetônicos e pedagógicos que apoiam o processo de projeto do edifício escolar, a partir de dados da literatura específica das duas áreas.
O programa arquitetônico escolar também é tema do artigo "O jogo como ferramenta de apoio ao programa arquitetônico de escolas públicas" das autoras Marcella Savioli Deliberador e, mais uma vez, Doris C.C.K. Kowaltowski, da Universidade Estadual de Campinas. Este artigo apresenta o desenvolvimento de uma ferramenta de apoio ao processo de projeto de escolas públicas, destacando-se o programa arquitetônico e os processos participativos. A ferramenta, em formato de um jogo de cartas, está baseada em parâmetros de projeto específicos da realidade brasileira, a partir dos requisitos da Fundação para o Desenvolvimento da Educação e da literatura. Segundo as autoras, o jogo media a elaboração do programa arquitetônico, através de um debate estruturado estimulando propostas inovadoras e contribuindo para a melhoria da educação.

O artigo "Evolução diurna do calor antropogênico liberado por cozinhas e sua relação com o balanço de energia à superfície no oeste paulista, SP" constitui uma contribuição para o entendimento do balanço de energia na superfície, a partir da relação entre diferentes escalas reconhecidas na paisagem, da escala urbana à escala pontual, em cidades localizadas nas áreas tropicais. Os autores - Gabriela Iassia Finati e Antonio Jaschke Machado da Universidade Estadual Paulista em Presidente Prudente - propõem um método de investigação que parte da caracterização térmica das faces interna e externa das paredes de cozinhas com diferentes intensidades de fontes de calor antropogênico associado à queima de gás liquefeito de petróleo. Pode-se perceber que cozinhas similares analisadas, embora localizadas no mesmo município e a menos de $1 \mathrm{~km}$ de distância apresentaram desempenho térmico diferente, assim como os demais resultados das medições e dos cálculos. Aponta-se a necessidade de que projetos similares de cozinhas sejam adaptados de acordo com as particularidades do local de inserção. São propostas soluções de projeto arquitetônico para melhorar as condições térmicas desses ambientes.

Condições térmicas, mas agora na escala urbana, é o tema do artigo "Efeitos da incorporação de vegetação em telhados de zona urbana em clima tropical continental". Os autores Karyna de Andrade Carvalho Rosseti, Luciane Cleonice Durante, Marta Cristina de Jesus Albuquerque Nogueira, Ivan Júlio Apolônio Callejas, Igor Antonio Kuhnen e José de Souza Nogueira - da Universidade Federal de Mato Grosso - avaliam, por simulação computacional, se a incorporação de vegetação nos telhados de edificações localizadas em zonas urbanas de baixo adensamento construtivo altera as condições termo higrométricas ao nível do pedestre. Verifica-se interferência entre a densidade de ocupação dos telhados pela vegetação e o fenômeno de arrefecimento e umidificação do ar ao nível do pedestre, em condições 
urbanas de baixo adensamento construtivo. Os efeitos mais expressivos estão contidos na região dos quintais a sotavento das casas que incorporaram a vegetação.

Finalmente, o artigo "Castelo Simões Lopes - um descaso com a história e o dinheiro público na cidade de Pelotas/RS" dos autores Ariela da Silva Torres e Miguel Tarouco Bezerra - da Universidade Federal de Pelotas evidencia o descaso ao tombamento de patrimônio, que ao contrário deveria impulsionar intervenções visando à conservação. Desenvolve-se uma análise sobre a edificação tombada por meio de levantamento visual e fotográfico das manifestações patológicas das fachadas, desdobrando-se em diagnósticos e indicações de possíveis soluções. Os autores salientam que a cada ano que o Castelo Simões Lopes é abandonado sem intervenção adequada, eleva-se o custo para os cofres públicos em obter novamente a beleza de sua edificação.

\section{Agradecimentos}

Agradecemos aos avaliadores pelo tempo despendido e valiosas considerações tecidas sobre os artigos submetidos.

\section{Referências}

ANDRADE, Max L. V. X. de; RUSCHEL, Regina Coeli; MOREIRA, Daniel de Carvalho. O processo e os métodos. In: KOWALTOWSKI, D.C.C.K.; MOREIRA, D.C.; PETRECHE, J.R.D.; FABRICIO, M.M.. (Org.). O processo de projeto em arquitetura: da teoria à tecnologia. 1ed. São Paulo: Oficina de Textos, 2011, p. 80-100.

BELTRAMIN, Renata Maria Geraldini. Caracterização e sistematização de quatro modelos de análise gráfica: Clark, Pause, Ching, Baker e Unwin. 2015. 148 p. Dissertação (mestrado) - Universidade Estadual de Campinas, Faculdade de Engenharia Civil, Arquitetura e Urbanismo, Campinas, SP.

DESCARTES, Renè. Discurso do Método. In: DESCARTES - Vida e Obra. São Paulo: Nova Cultural, 2004, p. 33-100. (Os Pensadores, 11).

JONES, John Christopher. A Method of Systematic Design. In: JONES, J. C. e THORNLEY, D. G. (Ed.). Conference on design methods. Oxford: Pergamon Press, 1963, p. 53-73.

MOREIRA, Daniel de Carvalho. Os princípios da síntese da forma e a análise de projetos arquitetônicos. 2007. $351 \mathrm{p}$. Tese (doutorado) - Universidade Estadual de Campinas, Faculdade de Engenharia Civil, Arquitetura e Urbanismo, Campinas, SP.

UNWIN, S. Analysing Architecture. London: Routledge, 1997.

VAN DER VOORDT, Theo J. M; VAN WEGEN, Herman B. R. Arquitetura sob o olhar do usuário: programa de necessidades, projeto e avaliação de edificações. São Paulo: Oficina de Textos, 2013.

\footnotetext{
${ }^{1}$ Daniel de Carvalho Moreira

Arquiteto. Doutor em Engenharia Civil (UNICAMP). Professor Doutor II (UNICAMP). Endereço postal: Av. Albert Einstein, 951, Campinas, SP, Brasil, CEP 13.083-852.

${ }^{2}$ Regina Coeli Ruschel

Engenheira Civil. Doutor em Engenharia Elétrica e da Computação (UNICAMP). Livre Docente em Projeto Auxiliado por Computador (UNICAMP). Endereço postal: Av. Albert Einstein, 951, Campinas, SP, Brasil, CEP 13.083-852
} 